\title{
ANTI-DIABETIC, ANTI-HYPERLIPIDEMIC AND HEPATOPROTECTIVE POTENTIAL OF SHADDOCK (CITRUS MAXIMA) PEEL EXTRACT
}

\author{
Peace Nwanneka Ani ${ }^{凶}$, Kalu Ezinne Ochu \\ Department of Nutrition and Dietetics, University of Nigeria, Nsukka \\ P.O. Box 3042, Enugu State, Nigeria
}

\begin{abstract}
Background. Diabetes is a serious public health problem which poses serious socio-economic burden at the national and global level. Most synthetic agents for treating diabetes are expensive and not devoid of adverse effect hence, the need for continuous effort in the search for affordable and natural effective treatment of diabetes. This study investigated the anti-diabetic, anti-hyperlipidemic, and hepatoprotective effects of Citrus maxima peel extract on alloxan-induced diabetic rats.

Materials and methods. Twenty-eight adult male Wistar rats were categorized into four groups of seven rats with similar body weights. Diabetes was induced using alloxan and baseline data obtained. Rats in groups A, $\mathrm{B}$, and $\mathrm{C}$ were administered with $200 \mathrm{mg}, 400 \mathrm{mg}$, and $600 \mathrm{mg}$ of Citrus maxima peel extract per kg body weight/day, respectively for 14 days. Group D (control) received $200 \mathrm{mg}$ of plain water per kg body weight/ day. Biochemical analyses of blood glucose, lipid profile, and liver enzyme activities were performed after the feeding trial. Data were analyzed using SPSS, version 21.

Results. Citrus maxima peel extract significantly decreased $(p<0.05)$ the blood glucose level by $70.17 \%$. The extract $(600 \mathrm{mg})$ resulted in a percentage increase in high-density lipoprotein cholesterol $(4.43 \%)$ and decrease in total cholesterol (30.86\%), triglyceride (10.58\%) and low-density lipoprotein cholesterol $(10.20 \%)$. Liver enzyme activities of the control groups significantly increased while the treated groups showed no significant change.

Conclusion. Citrus maxima peel extract has proven to be effective in diabetes management. However, use of standardized extract and proper laboratory tests are necessary.
\end{abstract}

Keywords: Citrus maxima, citrus peel, diabetes, hyperlipidemia, shaddock

\section{INTRODUCTION}

Diabetes mellitus is a chronic disease characterized by high blood glucose level and often associated with hyperlipidemia and liver abnormalities. Diabetes results due to the inability of the pancreas to produce enough insulin (a hormone that regulates blood glucose) or inefficient use of insulin produced. It accelerates the overall risk of dying prematurely due to its associated complications, which affects many parts of the body. Elevated blood glucose (hyperglycemia), a common effect of uncontrolled diabetes over time could damage the heart, blood vessels, eyes, kidneys, and nerves. Diabetes is one of the most common non-communicable diseases (NCDs) globally and the fourth leading cause of NCD deaths. Majority of people with diabetes live in low and middle-income countries. In 2012 alone diabetes caused 1.5 million death (WHO, 2016). Hyperglycemia caused an additional 2.2 million deaths, by increasing the risk of cardiovascular 
and other diseases. The global prevalence of diabetes among adults rose from 108 million in 1980 to 422 million in 2014 (WHO, 2018). The prevalence is projected to rise to 700 million by 2045 (IDF, 2017) without effective prevention and management programs. In 2013, IDF (2013) estimated the global healthcare expenditure for diabetes at $10.8 \%$ (548 billion USD) of the total annual healthcare expenditure. This amount is projected to 627 billion USD by 2035 . In Nigeria, the estimated annual direct cost of diabetes was between 1.071 billion to 1.639 billion USD per year. The high cost of treating diabetes is a major concern especially in developing countries where most patients with diabetes are poor and ignorant (Famuyiwa et al., 1985). Most synthetic agents for treating diabetes are expensive and not devoid of adverse effects. There is need for continuous effort in the search for cheap and natural effective treatment of diabetes. Plant-based constituents are always better options for their easy accessibility, acceptability, affordability and safety.

Citrus maxima also known as shaddock is a tropical fruit plant that originated from South East Asia and widely cultivated in some parts of West Africa. It is the largest of all citrus which is commonly used for ornamental purpose especially in West Africa. Many health benefits such as antitoxic, cardiac stimulant, appetizer, anti-diabetic, and hypocholesterolemic have been attributed to Citrus maxima pulp and juice (Ani and Aginam, 2018; Ontengco et al., 1995).

Citrus fruits are known to produce a large amount of waste especially when processed into fruit juice. Citrus by-products can provide a rich source of nutrients and bioactive compounds hence can offer significant low cost dietary and health supplements. Food products enriched with citrus peel are emerging due to the beneficial components they contain (Babiker et al., 2013). Citrus maxima by-products have been evaluated for their nutritive and bioactive compounds. The peel contains an appreciable amount of carbohydrate, calcium, phosphorus, sodium, water-soluble vitamins, and phytochemicals (Ani and Abel, 2018). Several studies have revealed a strong relationship between plant bioactive compounds and chronic disease risk reduction (Aanchal et al., 2019). This study aimed to determine the anti-diabetic, anti-hyperlipidemic, and hepatoprotective effects of Citrus maxima peel extract on diabetic rats.

\section{MATERIALS AND METHODS}

\section{Identification and preparation of samples}

The fruits were procured from a garden in Trans-Ekulu, Enugu State, Nigeria and identified at the Department of Plant Science and Biotechnology Department, Faculty of Biological Sciences, University of Nigeria, Nsukka. The fruits were thoroughly washed with distilled water and air-dried. The peel was separated from the pulp by hand and ground using a mechanical grinder. The peel $(500 \mathrm{~g})$ was macerated with 1000 $\mathrm{ml}$ of ethanol $(95 \% \mathrm{v} / \mathrm{v})$ for 2 days. The plant extract was filtered through filter paper and the residue was discarded. The filtrate was concentrated by rotary evaporation and the recovered peel-extract (58.9 g) was stored in refrigerator $\left(-4^{\circ} \mathrm{C}\right)$ until needed.

\section{Sourcing and housing of rats}

Twenty-eight (28) adult male Wistar rats aged 24 weeks old and weighing between 110-130 g were purchased from the Department of Veterinary Pathology, Faculty of Veterinary Medicine, University of Nigeria Nsukka, Nigeria. The experiment was carried out at the laboratory animal facility of the Department of Veterinary Pathology, Faculty of Veterinary Medicine, University of Nigeria Nsukka, Nigeria. The metabolic cages were washed with detergent and clean water, thoroughly disinfected and left to air dry to ensure a hygienic environment. Rats were distributed in the cages and maintained under standard environmental conditions of temperature $\left(27 \pm 2^{\circ} \mathrm{C}\right)$, humidity $(55 \pm 10 \%)$ and $12 \mathrm{~h}$ light-dark periodicity. The rats were divided into four groups (A, B, C, and D) of seven rats each based on body weight with a difference not more than $\pm 5 \mathrm{~g}$ per group.

\section{Induction of diabetes and feeding of the rats}

The animals were fed with palletized feed (Grand Cereals Ltd, Nigeria) and water ad libitum for five days to acclimatize them to the laboratory hygienic conditions and diet. They were made to fast overnight before injection of alloxan monohydrate (Sigma) dissolved in ice-cold normal saline at a dose of $150 \mathrm{mg} / \mathrm{kg}$ body weight via intraperitoneal. After an hour of alloxan administration, the rats were fed 5\% dextrose solution in a feeding bottle for a day to overcome the early hypoglycemic phase. They were kept under observation and after $48 \mathrm{~h}$ of induction, the blood glucose was 
determined using Accu-chek glucometer. Rats with blood glucose level of $\geq 200 \mathrm{mg} / \mathrm{dl}$ were considered diabetic and used in the study.

Rats in groups A, B, and C were fed $200 \mathrm{mg}, 400$ $\mathrm{mg}$, and $600 \mathrm{mg}$, respectively of the peel extract per $\mathrm{kg}$ body weight with rat chow and water ad libitum. Group D (control group) was fed $200 \mathrm{mg}$ of plain water with rat chow and water ad libitum. The peel extracts were first administered orally before feeding the rats for the day.

Blood samples were collected by an ocular puncture after induction (baseline) and at the end of the experiment to determine the values of the blood constituents. The study lasted for 21 days; 5 days of acclimatization, 2 days induction and 14 days of experimental study. The experimental procedures were according to the standard protocol approved by the animal ethics committee of Faculty of Veterinary Medicine, University of Nigeria, Nsukka.

\section{Biochemical analyses}

Blood glucose level was determined using Accuchek ${ }^{\circledR}$ glucometer (Accu-chek Performa, Roche) according to the manufacturer's instructions. Lipid profile (total cholesterol, low-density lipoprotein cholesterol (LDL-c), high-density lipoprotein cholesterol (HDL-c), and triglyceride) was determined by enzymatic colorimetric methods using commercial assay kits obtained from Randox International UK. These tests were carried out according to the manufacturer's protocol. Liver enzyme activities were determined based on the colorimetric measurements of hydrazone formed with 2,4-dinitrophenyl hydrazine (aspartate transaminase (AST) and alanine aminotransferase (ALT)), and phenolphthalein monophosphate method (alkaline phosphatase (ALP)) (Babson, 1965; Reitman and Frankel, 1957).

\section{Statistical analysis}

Data obtained were analyzed using the Statistical Package for Social Science (SPSS), version 21. Results were presented as mean with standard deviation. Paired sample T-test was used to compare before and after treatment of each group mean at a significant level of $p<0.05$.

\section{RESULTS AND DISCUSSION}

Anti-diabetic, anti-hyperlipidemic and hepatoprotective potential of Citrus maxima peel extract on alloxaninduced diabetic rats were investigated in this study.

\section{Anti-diabetic potential of Citrus maxima peel extract}

Treatment with Citrus maxima peel extract significantly decreased the blood glucose levels of rats in treated groups when compared to the control (Table 1). Highest percentage decrease in blood glucose level occurred

Table 1. Effect of Citrus maxima peel extract on fasting blood glucose level

\begin{tabular}{|c|c|c|c|c|}
\hline \multirow{2}{*}{$\begin{array}{l}\text { Fasting blood glucose } \\
\text { mg/dl }\end{array}$} & \multicolumn{4}{|c|}{ Group } \\
\hline & A & B & $\mathrm{C}$ & D (control) \\
\hline Before treatment & $381.00 \pm 68.99^{b}$ & $356.00 \pm 64.22^{\mathrm{b}}$ & $263.60 \pm 72.37^{\mathrm{d}}$ & $376.00 \pm 65.64^{a}$ \\
\hline After treatment & $144.60 \pm 20.88^{a}$ & $106.20 \pm 7.43^{\mathrm{a}}$ & $95.60 \pm 11.17^{\mathrm{a}}$ & $533.00 \pm 68.27^{b}$ \\
\hline$\%$ difference & $-62.05 \downarrow$ & $-70.17 \downarrow$ & $-63.73 \downarrow$ & $41.76 \uparrow$ \\
\hline$P$-value & 0.00 & 0.00 & 0.01 & 0.01 \\
\hline
\end{tabular}

Values $=$ mean \pm standard deviation.

Mean values in the same column with different superscripts are significantly different at $p<0.05$.

A - experimental group fed $200 \mathrm{mg}$ of Citrus maxima peel extract per kg body weight and rat chow with water ad libitum.

B - experimental group fed $400 \mathrm{mg}$ of Citrus maxima peel extract per kg body weight and rat chow with water ad libitum.

$\mathrm{C}$ - experimental group fed $600 \mathrm{mg}$ of Citrus maxima peel extract per kg body weight and rat chow with water ad libitum.

D - control group fed $200 \mathrm{mg}$ of plain water per kg body weight and rat chow with water ad libitum. 
with $400 \mathrm{mg}$ of the test sample. The anti-diabetic potential of Citrus maxima peel extract is associated with its wealth of phytochemicals. Earlier phytochemical analysis of Citrus maxima peel extract sourced from the same location as that used in the present study revealed high amount of alkaloid $(3498.37 \mathrm{mg} / 100 \mathrm{~g})$, phenolics $(1799.07 \mathrm{mg} / 100 \mathrm{~g})$, flavonoids $(1511.74 \mathrm{mg} / 100$ $\mathrm{g}$ ) and saponin $(24.51 \mathrm{mg} / 100 \mathrm{~g})$ (Ani and Abel, 2018). Phytochemicals are bioactive non-nutrient plant compounds that have been proven to reduce the risk of developing chronic diseases such as diabetes. Flavonoids and saponins are known for their beneficial effect in reducing blood glucose (Elekofehinti, 2015). The anti-diabetic effect of flavonoids is achieved through their ability to modulate glucose metabolism or insulin sensitivity at different levels, increase glucose uptake and insulin secretion, and inhibit glucose production (Alkhalidy et al., 2018). They also act by inhibiting the expression and translocation of glucose transporter (GLUT4). Previous studies (Patel et al., 2015) have shown that saponins not only have a hypoglycemic effect but also lower triglycerides hence exhibiting antidiabetic effect.

Our finding agrees with other studies which reported anti-diabetic properties of citrus peels. Kundusen et al. (2011) showed that extract of Citrus limetta had potent anti-hyperglycemic activity against streptozotocin-induced diabetic rats as well as hypoglycemic activity in normoglycemic rats. An investigation on the anti-diabetic activity of Citrus sinensis in diabetic rats revealed significantly reduced blood glucose when compared with the positive control (Muhtadi et al., 2015). In another study, the peel of Citrus sinensis showed some anti-diabetic properties as it reduced serum concentration of glucose in alloxan-induced diabetic rats (Luka et al., 2017).

In the present study, diabetes was induced using alloxan, a beta cytotoxin, which induces 'chemical diabetes' in a wide variety of animal species by damaging the insulin-secreting cells of the pancreas (Sharma et al., 2008). Antioxidants play important roles in inhibiting both free radicals and oxidative chain reactions within the tissues and cell membranes. Earlier study (Ani and Abel, 2018) reported a significant amount of antioxidant vitamins $\mathrm{E}$ and $\mathrm{C}$ in Citrus maxima peel extract. In addition to phytochemicals, the antidiabetic effect of Citrus maxima peel extract observed in the present study could be attributed to the antioxidant vitamins. The mechanism of action could be explained through the ability of the antioxidant vitamins to scavenge free radicals preventing alloxan-induced oxidative stress and protecting the $\beta$ cells. This will consequently increase insulin secretion and decrease elevated blood glucose levels. Plant extracts are known to exert anti-diabetic activity through enhancing cellular glucose uptake and activation of insulin release from the pancreatic $\beta$-cells (Gushiken et al., 2016).

\section{Anti-hyperlipidemic potential of Citrus maxima peel extract}

Citrus maxima peel extract exhibited serum lipidlowering properties. Percentage decline in total cholesterol, LDL-c and triglyceride was observed with administered doses of Citrus maxima peel extract with maximum reduction $(30.86 \%)$ in groups treated with $600 \mathrm{mg} / \mathrm{kg} \mathrm{BW}$ (Table 2). Increase in HDL-c level occurred only in groups treated with the highest dose $(600$ $\mathrm{mg} / \mathrm{kg} \mathrm{BW}$ ) of Citrus maxima peel extract. The control group had significantly $(p<0.05)$ higher increase in the LDL-c, total cholesterol, and triglyceride levels compared with the treated groups. These findings were in line with previous studies. Park et al. (2012) reported a significant reduction in total cholesterol of rats fed high doses (576 ml/day) of Citrus unshiu peel extract as compared to low doses. Mollace et al. (2011) also reported a significant increase in HDL-c while total cholesterol, LDL-c, and triglyceride decreased in rats fed citrus flavonoid-rich extract. Flavonoids are polyphenolic compounds that have antioxidant properties. Menichini et al. (2011) accredited the potential of citrus peel extract in plasma triglyceride reduction to the ability of citrus flavonoids to prevent oleic acid conjugation in triglycerides thus leading to an overall decrease in plasma cholesterol level. The citrus peel bioactive moieties trigger the activation of receptor cells that incorporate excess LDL-c and triglycerides into the liver and adipose tissue rather than circulating in the vascular system to form plaque. Similarly, citrus flavonoids decrease free fatty acids, triglycerides and increase fecal excretion of triglycerides (Menichini et al., 2011). The hypolipidemic effect of Citrus maxima peel extract in the present study could also be attributed to the antioxidant vitamins. Vitamin E and ascorbic 
Ani, P. N., Ochu, K. E. (2020). Anti-diabetic, anti-hyperlipidemic and hepatoprotective potential of shaddock (Citrus maxima) peel extract. Acta Sci. Pol. Technol. Aliment., 19(3), 271-278. http://dx.doi.org/10.17306/J.AFS.2020.0811

Table 2. Effect of Citrus maxima peel extract on lipid profile

\begin{tabular}{|c|c|c|c|c|}
\hline \multirow{2}{*}{$\begin{array}{l}\text { Lipid profile } \\
\text { mg/dl }\end{array}$} & \multicolumn{4}{|c|}{ Group } \\
\hline & A & $\mathrm{B}$ & $\mathrm{C}$ & $\mathrm{D}$ (control) \\
\hline \multicolumn{5}{|c|}{ High-density lipoprotein cholesterol } \\
\hline Before treatment & $76.80 \pm 9.23^{\mathrm{a}}$ & $79.20 \pm 8.56^{\mathrm{a}}$ & $72.20 \pm 11.84^{\mathrm{a}}$ & $80.20 \pm 7.09^{b}$ \\
\hline After treatment & $62.20 \pm 11.01^{\mathrm{a}}$ & $74.20 \pm 10.06^{\mathrm{a}}$ & $75.40 \pm 5.46^{\mathrm{a}}$ & $11.00 \pm 2.83^{\mathrm{a}}$ \\
\hline$\%$ difference & $-19.01 \downarrow$ & $-6.31 \downarrow$ & $4.43 \uparrow$ & $-86.28 \downarrow$ \\
\hline$P$-value & 0.05 & 0.42 & 0.60 & 0.00 \\
\hline \multicolumn{5}{|c|}{ Low-density lipoprotein cholesterol } \\
\hline Before treatment & $17.80 \pm 3.90^{\mathrm{a}}$ & $15.20 \pm 3.63^{\mathrm{a}}$ & $19.60 \pm 2.88^{\mathrm{a}}$ & $13.60 \pm 3.36^{\mathrm{a}}$ \\
\hline After treatment & $14.60 \pm 3.97^{\mathrm{a}}$ & $14.10 \pm 2.28^{\mathrm{a}}$ & $17.60 \pm 2.61^{\mathrm{a}}$ & $65.20 \pm 3.96^{\mathrm{b}}$ \\
\hline$\%$ difference & $-17.98 \downarrow$ & $-7.24 \downarrow$ & $-10.20 \downarrow$ & $379.41 \uparrow$ \\
\hline$P$-value & 0.24 & 0.53 & 0.28 & 0.00 \\
\hline \multicolumn{5}{|c|}{ Total cholesterol } \\
\hline Before treatment & $92.80 \pm 8.79^{\mathrm{a}}$ & $88.20 \pm 5.85^{\mathrm{a}}$ & $88.80 \pm 2.68^{b}$ & $92.60 \pm 5.55^{\mathrm{a}}$ \\
\hline After treatment & $85.40 \pm 5.81^{\mathrm{a}}$ & $76.60 \pm 11.61^{\mathrm{a}}$ & $61.40 \pm 1.67^{\mathrm{a}}$ & $112.60 \pm 3.91^{\mathrm{b}}$ \\
\hline$\%$ difference & $-7.97 \downarrow$ & $-13.15 \downarrow$ & $-30.86 \downarrow$ & $21.60 \uparrow$ \\
\hline$P$-value & 0.16 & 0.08 & 0.00 & 0.00 \\
\hline \multicolumn{5}{|c|}{ Triglycerides } \\
\hline Before treatment & $118.00 \pm 5.61^{\mathrm{a}}$ & $105.00 \pm 9.11^{\mathrm{b}}$ & $109.60 \pm 2.88^{\mathrm{b}}$ & $108.60 \pm 4.98^{\mathrm{a}}$ \\
\hline After treatment & $111.40 \pm 7.40^{\mathrm{a}}$ & $91.60 \pm 7.13^{\mathrm{a}}$ & $98.00 \pm 5.48^{\mathrm{a}}$ & $128.60 \pm 8.47^{\mathrm{b}}$ \\
\hline$\%$ difference & $-5.59 \downarrow$ & $-12.76 \downarrow$ & $-10.58 \downarrow$ & $18.42 \uparrow$ \\
\hline$P$-value & 0.15 & 0.03 & 0.00 & 0.00 \\
\hline
\end{tabular}

Values $=$ mean \pm standard deviation

Mean values in the same column with different superscripts are significantly different at $p<0.05$.

A - experimental group fed $200 \mathrm{mg}$ of Citrus maxima peel extract per kg body weight and rat chow with water ad libitum.

B - experimental group fed $400 \mathrm{mg}$ of Citrus maxima peel extract per $\mathrm{kg}$ body weight and rat chow with water ad libitum.

$\mathrm{C}$ - experimental group fed $600 \mathrm{mg}$ of Citrus maxima peel extract per $\mathrm{kg}$ body weight and rat chow with water ad libitum.

$\mathrm{D}$ - control group fed $200 \mathrm{mg}$ of plain water per $\mathrm{kg}$ body weight and rat chow with water ad libitum.

acid protect LDL-c from oxidative damage in vitro as reported in previous studies (Babiy et al., 1990; Jialal et al., 1990).

\section{Hepatoprotective effect of Citrus maxima peel extract}

The liver is an important organ with vital functions of detoxification and synthesis of useful substances.
Abnormalities or injury to the organ often manifests in elevated liver enzymes as they are spilled into the bloodstream. The occurrence of liver disease and increased liver enzyme activities are common among diabetic patients (Forlani et al., 2008). Our findings demonstrated that treatment with Citrus maxima peel extract had a hepatoprotective effect on diabetic rats as the serum liver enzyme activities (ALT, AST, and 
Ani, P. N., Ochu, K. E. (2020). Anti-diabetic, anti-hyperlipidemic and hepatoprotective potential of shaddock (Citrus maxima) peel extract. Acta Sci. Pol. Technol. Aliment., 19(3), 271-278. http://dx.doi.org/10.17306/J.AFS.2020.0811

Table 3. Effect of Citrus maxima peel extract on liver enzyme activities

\begin{tabular}{|c|c|c|c|c|}
\hline \multirow{2}{*}{$\begin{array}{l}\text { Liver enzyme activities } \\
\text { IU/L }\end{array}$} & \multicolumn{4}{|c|}{ Group } \\
\hline & A & $\mathrm{B}$ & $\mathrm{C}$ & $\mathrm{D}$ (control) \\
\hline \multicolumn{5}{|c|}{ ALT enzyme activity } \\
\hline Before treatment & $42.80 \pm 3.35^{\mathrm{a}}$ & $40.00 \pm 1.58^{\mathrm{a}}$ & $40.60 \pm 1.34^{\mathrm{a}}$ & $44.00 \pm 4.18^{\mathrm{a}}$ \\
\hline After treatment & $43.40 \pm 4.56^{\mathrm{a}}$ & $41.80 \pm 2.68^{\mathrm{a}}$ & $43.80 \pm 5.40^{\mathrm{a}}$ & $85.40 \pm 3.58^{b}$ \\
\hline$\%$ difference & $1.40 \uparrow$ & $4.50 \uparrow$ & $7.88 \uparrow$ & $94.09 \uparrow$ \\
\hline$P$-value & 0.82 & 0.23 & 0.24 & 0.00 \\
\hline \multicolumn{5}{|c|}{ AST enzyme activity } \\
\hline Before treatment & $63.40 \pm 3.97^{\mathrm{a}}$ & $64.60 \pm 5.73^{\mathrm{a}}$ & $63.40 \pm 3.85^{\mathrm{a}}$ & $67.40 \pm 5.18^{\mathrm{a}}$ \\
\hline After treatment & $65.00 \pm 4.00^{\mathrm{a}}$ & $66.00 \pm 5.48^{\mathrm{a}}$ & $61.20 \pm 3.11^{\mathrm{a}}$ & $99.60 \pm 7.40^{\mathrm{b}}$ \\
\hline$\%$ difference & $2.52 \uparrow$ & $2.17 \uparrow$ & $-3.47 \downarrow$ & $47.77 \uparrow$ \\
\hline$P$-value & 0.54 & 0.70 & 0.35 & 0.00 \\
\hline \multicolumn{5}{|c|}{ ALP enzyme activity } \\
\hline Before treatment & $55.40 \pm 1.95^{\mathrm{a}}$ & $55.80 \pm 3.49^{\mathrm{a}}$ & $52.60 \pm 2.41^{\mathrm{a}}$ & $62.40 \pm 4.34^{\mathrm{a}}$ \\
\hline After treatment & $52.80 \pm 3.96^{\mathrm{a}}$ & $55.00 \pm 4.36^{\mathrm{a}}$ & $51.40 \pm 2.97^{\mathrm{a}}$ & $98.80 \pm 9.68^{b}$ \\
\hline$\%$ difference & $-4.69 \downarrow$ & $-1.43 \downarrow$ & $-2.28 \downarrow$ & $58.33 \uparrow$ \\
\hline$P$-value & 0.24 & 0.76 & 0.50 & 0.00 \\
\hline
\end{tabular}

Values $=$ mean \pm standard deviation .

Mean values in the same column with different superscripts are significantly different at $p<0.05$.

A - experimental group fed $200 \mathrm{mg}$ of Citrus maxima peel extract per kg body weight and rat chow with water ad libitum.

$\mathrm{B}$ - experimental group fed $400 \mathrm{mg}$ of Citrus maxima peel extract per kg body weight and rat chow with water ad libitum.

$\mathrm{C}$ - experimental group fed $600 \mathrm{mg}$ of Citrus maxima peel extract per kg body weight and rat chow with water ad libitum.

$\mathrm{D}$ - control group fed $200 \mathrm{mg}$ of plain water per kg body weight and rat chow with water ad libitum.

ALP) of the control group increased significantly while the treated groups showed no significant change (Table 3). These findings are similar to other studies on the hepatoprotective effect of citrus peel. Chowdhury et al. (2015) found that increased liver enzyme activities (ALT, AST, and ALP) of carbon tetrachloride treated rats normalized after Citrus maxima peel powder supplementation. This was supported by Casimiro et al. (2010) who reported a significant decrease in liver enzymes (AST and ALT) after treating acetaminophen-induced liver damage in male rats with Citrus microcarpa bunge fruit peel extract. The hepatoprotective effect of Citrus peel extracts is associated with phytochemicals and antioxidant vitamins which exert multiple effects in this mechanism. Phytochemicals demonstrate hepatoprotection through antioxidant effect, and other ways such as immunomodulatory, antiviral, and anti-inflammatory. Scientific reports have shown that antioxidant therapy is generally protective in most if not all forms of liver diseases (Hanje et al., 2006). Antioxidant protective mechanisms are demonstrated through their ability to either block the formation of free radicals or inactivate/scavenge them.

Conclusively, the blood glucose level of the treated rats significantly reduced revealing the potential of $\mathrm{Ci}$ trus maxima peel extract in controlling diabetes. The risk of coronary heart diseases could be minimized with this extract as it improved HDL-c and reduced total cholesterol, and triglycerides, especially at high doses. The peel extract demonstrated a protective 
effect on the liver of diabetic rats when compared to the untreated (control) group. Citrus maxima peel extract therefore, had anti-diabetic, anti-hyperlipidaemic and hepatoprotective properties and could be effective in the treatment of diabetes and its complications. However, the use of standardized extract and proper laboratory tests are necessary.

\section{REFERENCES}

Aanchal, W., Amit, K. G., Vatsala, S. (2019). Role of bioactive compounds in human health. ASMS, 3(9), 25-33.

Alkhalidy, H., Wang, Y., Liu, D. (2018). Dietary flavonoids in the prevention of T2D: An overview. Nutrients, 10.

Ani, P. N., Abel, H. C. (2018). Nutrient. Phytochemical and anti-nutrient composition of Citrus maxima fruit juice and peel extract. Food Sci. Nutr., 6, 653-658.

Ani, P. N., Aginam, P. C. (2018). Effect of Citrus maxima juice on fasting blood glucose, lipid profile, liver enzyme and body weight. Nutr. Food Sci., 48, 755-763.

Babiker, W. A. M., Sulieman, A. M. E., Elhardallou, S. B., Khalifa, E. A. (2013). Physicochemical properties of wheat bread supplemented with orange peel by-products. Int. J. Food Sci. Nutr., 2, 1-4.

Babiy, A. V., Gebiciki, J. M., Sullivan, D. R. (1990). Vitamin E content and low density lipoprotein oxidizability induced by free radicals. Atherosclerosis, 81, 175-182.

Babson, L. A. (1965). Estimation of alkaline phosphatase activity. Clin. Chem., 11, 789.

Casimiro, M., Gutierrez, M., Leano, D., Solidum, J. (2010). Evaluation of the hepatoprotective activity of Citrus microcarpa Bunge (Family Rutaceae) fruit peel against acetaminopheninduced liver damage in male BFAD-Sprague Dawley rats. Int. J. Chem. Environ. Eng., 1, 127.

Chowdhury, M. R. H., Sagor, A. T., Tabassum, N., Potol, A., Hossain, H., Alam, A. (2015). Supplementation of Citrus maxima peel powder prevented oxidative stress, fibrosis, and hepatic damage in carbon tetrachloride $\left(\mathrm{CCl}_{4}\right)$ treated rats. Evid. Based Compl. Altern. Med., 2, 1-10. http://dx.doi.org/10.1155/2015/598179

Elekofehinti, O. O. (2015). Saponins: Anti-diabetic principles from medicinal plants - A review. Pathophysiol., $22,95-103$.

Famuyiwa, O. O., Edozien, E. M., Ukoli, C. O. (1985). Social, cultural and economic factors in the management of diabetes mellitus in Nigeria. Afr. J. Med. Med. Sci., $14,145-154$.

Forlani, G., Di Bonito, P., Mannucci, E., Capaldo, B., Genovese, S., Orrasch, M...Marchesini, G. (2008).
Prevalence of elevated liver enzymes in Type 2 diabetes mellitus and its association with the metabolic syndrome. J. Endocrinol. Invest., 31, 146-152.

Gushiken, L. F., Beserra, F. P., Rozza, A. L., Bérgamo, P. L., Bérgamo, D. A., Pellizzon, C. H. (2016). Chemical and biological aspects of extracts from medicinal plants with antidiabetic effects. Rev. Diabet. Stud., 13, 96-112.

Hanje, A. J., Fortune, B., Song, M., Hill, D., McClain, C. (2006). The use of selected nutrition supplements and complementary and alternative medicine in liver disease. Nutr. Clin. Pract., 21(3), 255-272.

IDF (2013). IDF Diabetes Atlas. International Diabetes Federation. Brussels, Belgium: International Diabetes Federation 160. www.idf.org/diabetesatlas.

IDF (2017). International Diabetes Federation (eighth ed.). Lancet, 388, 1659-1724.

Jialal, I., Vega, G. L., Grundy, S. M. (1990). Physiologic levels of ascorbate inhibit the oxidative modification of low density lipoprotein. Atherosclerosis, 82, 185-191.

Kundusen, S., Haldar, P. K., Gupta, M., Mazumder, U. K., Saha, P., Bala, A., ..., Kar, B. (2011). Evaluation of antihyperglycemic activity of Citrus limetta fruit peel in streptozotocin-induced diabetic rats. ISRN Endocrinol., 869273. https://dx.doi.org/10.5402/2011/869273

Luka, C. D., Istifanus, G., George, M., Philip, C. J. (2017). The effect of aqueous extract of Citrus sinensis peel on some biochemical parameters in normal and alloxan-induced diabetic wister rats. Am. J. Phytomed. Clin. Ther., 5, 1-8. Menichini, F., Loizzo, M. R., Bonesi, M., Conforti., De Luca, D., Statti, G. A., ..., Tundis, R. (2011). Phytochemical profile, antioxidant, anti-inflammatory and hypoglycemic potential of hydroalcoholic extracts from Citrus medicca L. cv Diamante flowers, leaves and fruits at two maturity stages. Food Chem. Toxicol., 49, 1549-1555.

Mollace, V., Sacco, I., Janda, E., Malara, C., Ventrice, D., Colica, C., ..., Romeo, F. (2011). Hypolipemic and hypoglycaemic activity of bergamot polyphenols: from animal models to human studies. Fitoterapia, 82, 309-316.

Muhtadi, Haryoto, Azizah, T., Suhendi, A., Yen, K. H. (2015). Antidiabetic and antihypercholesterolemic activities of Citrus sinensis peel: in vivo study. Natl. J. Physiol. Pharm. Pharmacol., 5(5), 382-385.

Ontengco, D. C., Dayap, L. A., Capal, T. V. (1995). Screening for the antibacterial activity of essential oils from some Philippine plants. Acta Manil., 43, 19-23.

Park, H. Y., Park, Y., Lee, Y., Noh, S. K., Sung, E. G., Choi, I. (2012). Effect of oral administration of water-soluble extract from citrus peel (Citrus unshiu) on suppressing alcohol-induced fatty liver in rats. Food Chem., 130, 598-604. 
Ani, P. N., Ochu, K. E. (2020). Anti-diabetic, anti-hyperlipidemic and hepatoprotective potential of shaddock (Citrus maxima) peel extract. Acta Sci. Pol. Technol. Aliment., 19(3), 271-278. http://dx.doi.org/10.17306/J.AFS.2020.0811

Patel, S. B., Santani, D., Patel, V., Shah, M. (2015). Antidiabetic effects of ethanol extract of Bryonialaciniosa seeds and its saponins rich fraction in neonatally streptozotocin-induced diabetic rats. Pharmacogn. Res., 7, 92-99.

Reitman, S., Frankel, S. (1957). Determination of glutamicoxaloacetic transaminase. Am. J. Clin. Pathol., 28(13), $56-59$.

Sharma, M., Fernandes, J., Ahirwar, D., Jain, R. (2008). Hypoglycemic and hypolipidimic activity of alcoholic extract of Citrus aurantium in normal and alloxan-induced diabetic rats. Pharmacologyonline, 3, 161-171. WHO (2018). Diabetes fact sheet. Retrieved March 24, 2020 from https://www.who.int/news-room/fact-sheets/ detail/diabetes

WHO (2016). Global report on diabetes. Retrieved March 24, 2020 from www.who.int > diabetes > global-report 